\title{
THE CHARACTERIZATION OF TRANS-PECOS COPPERHEAD (Agkistrodon contortrix pictigaster) VENOM AND ISOLATION OF TWO NEW DIMERIC DISINTEGRINS
}

Sara Lucena ${ }^{\mathrm{a} \S}$, Alexis Rodríguez-Acosta ${ }^{\mathrm{d} \S}$, Elyse Grilli ${ }^{\mathrm{a}}$, Andrea Alfonso ${ }^{\mathrm{c}}$, Amber Goins $^{c}$, Ifunanya Ogbata ${ }^{\mathrm{a}}$, Robert Walls ${ }^{\mathrm{a}}$, Montamas Suntravat ${ }^{\mathrm{a}}$, Nestor L. Uzcátegui ${ }^{\mathrm{d}}$, Belsy Guerrero ${ }^{\mathrm{e}}$, Elda E. Sánchez ${ }^{\mathrm{a}, \mathrm{b} *}$

${ }^{a}$ National Natural Toxins Research Center (NNTRC), Texas A\&M University-Kingsville, MSC 158, 975 West Avenue B, Kingsville, TX 78363, USA. ${ }^{b}$ Department of Chemistry, Texas A\&M University-Kingsville, MSC 161, Kingsville, TX 78363, USA. 'Biology Department, Del Mar College, 101 Baldwin Blvd., Corpus Christi, TX 78404, USA. ${ }^{\mathrm{d}}$ Laboratorio de Inmunoquímica y Ultraestructura, Instituto Anatómico de la Universidad Central de Venezuela, Caracas 1041, Venezuela. ${ }^{e}$ Laboratorio de Fisiopatología, Centro de Medicina Experimental, Instituto Venezolano de Investigaciones Científicas, Caracas 1020A, Venezuela.

*Corresponding author: Dr. Elda E. Sánchez, Texas A\&M University, National Natural Toxins Research Center, Department of Chemistry, MSC 224, 975 W. Avenue B, Kingsville, TX 78363, USA. Tel.: +1 361593 3796; fax: +1 3615933798.

E-mail address: elda.sanchez@tamuk.edu

$\S$ Authors contributed equally 


\begin{abstract}
.
The vast amounts of toxins within the venom of snakes, while known to cause medical emergencies, display various biological functions. Trans-Pecos copperhead (Agkistrodon contortrix pictigaster) crude venom separated by cation-exchange chromatography showed several fractions with fibrinolytic, hemorrhagic, gelatinase and platelet activities. Venom fractions 1, 2, 4, 5, and 12-17 contained fibrinolytic activity. Venom fractions 1, 2, 5 and 12-14 had hemorrhagic activity. Fractions 1, 2, 12-13 and 17 contained gelatinase activity. Reverse-Phase C18 High Performance Liquid Chromatography was also used to purify and isolated disintegrins from this venom. Antiplatelet aggregation activity of the $\mathrm{C} 18$ fractions collected and performed on whole human blood showed that they inhibited platelet aggregation in presence of several agonists. Results from both SDS-PAGE and N-terminal sequencing determined that pictistatin 1 obtained from the Trans-Pecos copperhead venom was a dimeric disintegrin, and pictistatin 2 was a heterodimeric disintegrin. The molecules with anti-platelet activity could be considered in the development of more effective drugs, for numerous bloodrelated diseases such as stroke, heart attacks, thrombosis, and other medical conditions. In this study, we are presenting the first report of the purification, isolation, and partial characterization of two new dimeric disintegrins isolated from the venom of Trans-Pecos copperhead.
\end{abstract}

Keywords: aggregation, dimeric disintegrins, platelets, venom, pictistatin. 


\section{Introduction}

Trans-pecos copperhead (Agkistrodon contortrix pictigaster) is a pit viper located in the Chihuahua desert of west Texas (Val Verde, Presidio, Crockett, and Upton Counties), and Westward from the Davis Mountains south through the Big Bend Mountains. This species is sympatric in eastern Val Verde County, with the broad-banded copperhead (Agkistrodon contortrix laticintus), which has been described in the western areas of the United States, from the southern regions of Kansas and Oklahoma states to the north of Texas state $[1,2]$.

The venoms from the genus Agkistrodon contain molecules that act on hemostasis, such as inhibiting glycoprotein (GP) IIb/IIIa mediated platelet aggregation. A prime example is contortrostatin $(\mathrm{Mr}=15,000)$ purified from the venom of Agkistrodon contortrix contortrix, which inhibits ADP-induced human platelet aggregation using platelet rich plasma (PRP); contortrostatin also showed GPIIb/IIIa unambiguously binding to human platelets, inhibiting platelet aggregation [3]. Previously, Stocker et al. (1986) [4] testing Agkistrodon contortrix contortrix, A. c. mokasen, A. c. pictigaster, Agkistrodon piscivorus, A. p. leucostoma, and A. bilineatus snake venoms were able to generate amidolytic activity with the chromogenic protein $\mathrm{C}$ substrate (D-Pro-L-Pro-LArg-pNA). In the venom of this genus, a serine proteinase with pro-coagulant activity has also been described [5]. Trans-pecos copperhead (Agkistrodon contortrix pictigaster) venom has been studied in regards to the genetic variation of a disintegrin gene found in all subspecies of the copperhead snake [6].

Agkistrodon venoms are highly hemolytic, containing high levels of phospholipase A2s, with the presence of phosphomonoesterase, L-amino oxidase and hyaluronidase activity that act on hemostasis and extracellular matrix proteins [7]. For instance, Johnson and Ownby (1993) [8] isolated a $29 \mathrm{kDa}$ hemorrhagic metalloproteinase toxin from $A$. c. laticintus venom with in vitro activity towards casein and bovine fibrinogen and also containing fibrinolytic enzymes aided by non-enzymatic disintegrins causing hemorrhaging [9]. Snake venom disintegrins exemplify a family of RGD (Arg-Gly-Asp), MLD (Met-Leu-Asp), VGD (Val-Gly-Asp), MGD (Met-Gly-Asp), WGD (Trp-Gly-Asp), MVD (Met-Val-Asp), KTS (Lys-Thr-Ser), RTS (Arg-Thr-Ser) or KGD (Lys-Gly-Asp)-containing protein molecules that have been described as distinctive 
and potentially valuable tools not only for researching interactions between integrins and their ligands, but also for the improvement of anti-thrombotic agents in relations to their activities on platelets [10]. The symptoms of Agkistrodon bites include nausea, vomiting, pain, edema, bleeding, gangrene, bruising, fever, headache, intestinal discomfort, shortness of breath, and shock [2,11]. Agkistrodon bites are common, but death due to them is virtually nonexistent; the fatality rate has been estimated to be as low as 0.01 $0.3 \%[2]$.

In the present work, we have found that A. $c$. pictigaster venom has dimeric disintegrins that contain anti-platelet effects on human blood, but do not affect the proliferation of four different cancer cell lines. This is the first report of the purification, isolation and partial characterization of two new dimeric disintegrins isolated from the venom of trans-pecos copperheads.

\section{Materials and Methods}

\subsection{Venom collection}

A trans-pecos copperhead (A. c. pictigaster) (Avid \#010-512-028) was captured in West Texas, U-S-A. Venom was collected in the National Natural Toxins Research Center (NNTRC), Texas A\&M University-Kingsville, Kingsville, TX, USA and was obtained by permitting the snake to bite into Para-film stretched over a disposable plastic cup. Each venom sample was centrifuged in a Beckman Avanti 30, at 10,000 x g for 5 min, filtered through a Millipore filtration MillexHV unit $0.45 \mu \mathrm{m}$ under positive pressure, and lyophilized. Venom was kept at $-90^{\circ} \mathrm{C}$ until use.

\subsection{Ethical statement}

Skilled personnel arranged all the experimental techniques relating to the use of live animals. Pertinent regulations as well as institutional guidelines, according to protocols ratified by the National Natural Toxins Research Center, Texas A\&M University-Kingsville, Texas, USA (Viper Resource Center at Texas A\&M UniversityKingsville, IACUC \#: 2012-12-18A-A4) and the Institute of Anatomy of the Universidad Central de Venezuela following the norms obtained from the guidelines for the care and use of laboratory animals, published by the US National Institute of Health (NIH 1985) [12]. 


\subsection{Protein purification}

\subsubsection{Cation-exchange chromatography}

Agkistrodon c. pictigaster venom was fractionated with a cation-exchange chromatography column (Waters ${ }^{\mathrm{TM}} \mathrm{SP} 5 \mathrm{PW}, 75 \mathrm{x} 7.5 \mathrm{~mm}$ ) in order to test hemorrhagic, proteolytic, fibrinolytic, and gelatinase activities. Fractions were separated using 0.02M sodium phosphate buffer at $\mathrm{pH} 6.2$, with a $0.5 \mathrm{M} \mathrm{NaCl}$ gradient for $60 \mathrm{~min}$, with a rate of flow of $1 \mathrm{~mL} / \mathrm{min}$. An adjustable detector Waters 484 was used to monitor the absorbance at $280 \mathrm{~nm}$.

After that, the crude venom was directly run through a reverse phase C18 chromatography column, in order to test the inhibition of platelet aggregation, and isolate molecules with disintegrin activity and carry out proliferation inhibition studies.

\subsubsection{C18-reverse phase chromatography}

Ten milligrams of lyophilized crude copperhead venom were reconstituted in 200 $\mu \mathrm{L}$ of $0.1 \%$ trifluoroacetic acid (TFA; solution A) and filtered through a $0.45 \mu \mathrm{m}$ filter. The venoms were then fractionated by reverse phase chromatography using a Higgins Analytical PROTO 300 C18 (250 x 4.6 mm, $5 \mu \mathrm{m})$ column. Fractions were eluted using a $0.1 \%$ TFA, and $80 \%$ acetonitrile in $0.1 \%$ TFA (solution B) gradient over 60 min, with a flow rate of $1 \mathrm{~mL} / \mathrm{min}$. A Waters 2487 Dual Absorbance detector was used to monitor absorbances at $280 \mathrm{~nm}$. Fractions were stored at $-80^{\circ} \mathrm{C}$. Protein concentrations were determined by standard methods at $280 \mathrm{~nm}$ using an extinction coefficient of $1[13,14$, 15].

\subsubsection{Centrifugal fractionation}

Five hundred microliters of Pictistatin 1 and $2(1 \mathrm{mg} / \mathrm{mL})$ obtained by reverse phase chromatography were centrifuge-fractionated using a Millipore Micron YM-3 3.0 $\mathrm{kD}$ cutoff centrifugal filters (Bedford, MA, USA). The supernatant was subjected to gel electrophoresis.

\subsection{SDS Polyacrylamide Gel Electrophoresis}


Forty micrograms of disintegrin samples were electrophoresed using a precast 10$20 \%$ Tricine gel in an XCell SureLock ${ }^{\mathrm{TM}}$ Mini-Cell (Invitrogen, USA) at $125 \mathrm{~V}$ for 90 min. Gels were stained with SimplyBlue ${ }^{\mathrm{TM}}$ SafeStain (Life Technologies, USA).

\subsection{Gelatinase activity}

A modified method by Huang and Perez (1980) [16] was used to test the gelatinase activity of A. c. pictigaster crude venom and fractions. An X-ray film (Kodak $\mathrm{X}$-OMAT) was washed with distilled water and incubated at $37^{\circ} \mathrm{C}$ for $45 \mathrm{~min}$. After incubation, the film was thoroughly dried, and $20 \mu \mathrm{L}$ of serially diluted crude venom or fractions (starting at $50 \mu \mathrm{g}$ protein) were located on the X-ray scientific imaging film containing a gelatin coating. The X-ray film was incubated for $2 \mathrm{~h}$ at $37^{\circ} \mathrm{C}$ in a humid incubator. Washing the film with distilled water and observing a clear area determined hydrolysis of gelatin. Serial dilutions were performed to determine the minimum amount of venom required to cause a clear spot on the film. The titer was defined as the reciprocal of the highest dilution that produced a clear spot on the film. The specific gelatinase activity was calculated by dividing the titer by the amount of protein $(\mu \mathrm{g})$ applied on the film. The analysis was repeated 3 times.

\subsection{Hemorrhagic analysis}

To determine the hemorrhagic activity of A. c. pictigaster venom and fractions, a modified Omori-Satoh et al. (1972) [17] method was used. One hundred microliters (100 $\mu \mathrm{L}$ ) of crude venom and individual fractions were intracutaneously injected (i.c.) into the back of a New Zealand rabbit. The rabbit was sacrificed after $18 \mathrm{~h}$ and skin was removed. Hemorrhagic activity was determined by the presence of a hemorrhagic spot on the skin. Specific hemorrhagic activity was determined by dividing the size of the hemorrhagic point $(\mathrm{mm})$ by the amount of injected protein $(\mu \mathrm{g})$. This activity was compared with minimum hemorrhagic dose (MHD: $2.5 \mu \mathrm{g}$ ) of Crotalus atrox crude venom.

\subsection{Fibrinolytic analysis}

To measure the fibrinolytic activity of $A$. c. pictigaster venom fractions the modified Bajwa et al. (1982) [18] method was used. Three hundred microliters (300 $\mu \mathrm{L})$ of fibrinogen and 12 microliters $(12 \mu \mathrm{L})$ of thrombin solution were added to each well of a 24-well plate and softly agitated. The plate was kept at room temperature until content solidified; then the plate was incubated at $37^{\circ} \mathrm{C}$ for $3 \mathrm{~h}$. Twenty microliters $(20 \mu \mathrm{L})$ of 
each fraction were added to each well and additionally incubated at $37^{\circ} \mathrm{C}$ for another 15 h. Then, $700 \mu \mathrm{l}$ of $10 \%$ trichloroacetic acid were placed at each well to stop the reaction, decanting after $10 \mathrm{~min}$. Specific fibrinolytic activity was calculated by dividing the cleared fibrin area (millimeters) by the amount of protein $(\mu \mathrm{g})$ in each well.

\subsection{Inhibition of platelet aggregation}

The inhibition of platelet aggregation study was done according to the Sánchez et al. (2010) [19] method using a dual-channel Chronolog-Log Whole-Blood Aggregometer $\left[\mathrm{Ca}^{+} 2\right]$ model 560 (Havertown, USA). Briefly, different concentrations of venom fractions $(10 \mu \mathrm{L})$ from $\mathrm{C} 18$-reverse phase chromatography were added to $10 \%$ citrated human whole blood, and pre-incubated at $37^{\circ} \mathrm{C}$ for $2 \mathrm{~min}$.

Platelet aggregation was initiated by $10 \mu \mathrm{L}$ of ADP $(10 \mu \mathrm{M}), 2 \mu \mathrm{L}$ of collagen ( 2 $\mu \mathrm{g} / \mathrm{mL}), 8 \mu \mathrm{L}$ of ristocetin $(1 \mathrm{mg} / \mathrm{mL}), 5 \mu \mathrm{L}$ of epinephrine $(50 \mu \mathrm{M})$, or $10 \mu \mathrm{L}$ of arachidonic acid $(50 \mu \mathrm{M})$, and the percentage of impedance reflecting aggregation percentage was measured. The maximal aggregation in the absence of venom fractions was reported as $100 \%$ aggregation.

\section{9. $\mathrm{N}$-terminal sequencing}

Fractions from C18-reverse phase chromatography having anti-platelet activities were transferred from SDS-PAGE 10-20\% Tricine gel onto a PVDF membrane (Millipore, Immobilon-P) using a Semi-Dry Transblot Cell (Bio-Rad, USA) at $25 \mathrm{~V}$ for 1 h. The membrane was stained with Coomassie R-250 stain for $2 \mathrm{~h}$. The membrane was sent to the Iowa State University for N-terminal amino acid sequencing of the first 12 amino acids.

\subsection{Proliferation inhibition studies}

Anti-proliferation activity was performed according to the Lucena et al. (2015) [20] method, by measuring cell proliferation using MTT (3-(4, 5-Dimethylthiazol-2-yl)-2, 5-diphenyltetrazolium bromide) and fractions from C18-reverse phase chromatography. Pictistatin 1 and 2 were assayed using four different cancer cell lines (human pancreatic carcinoma (BXPC-3), human urinary bladder carcinoma (T24), human skin melanoma (SK-MEL-28), and human leukemia (K-562)). Briefly, two hundred microliters of cells were cultured in duplicate in 96-well flat-bottom microtiter plates, at $10^{5}$ cells/well, and incubated at $37^{\circ} \mathrm{C}$ in $5 \% \mathrm{CO}_{2}$ for $24 \mathrm{~h}$. 
Twenty microliters of each disintegrin at various concentrations were added to the cell suspension at $37^{\circ} \mathrm{C}$ for $48 \mathrm{~h}$. Then, $10 \mu \mathrm{L}$ of MTT $(5 \mathrm{mg} / \mathrm{mL})$ was added to each well. After incubation for $4 \mathrm{~h}$ at $37^{\circ} \mathrm{C}$, MTT was aspirated, and $100 \mu \mathrm{L}$ of DMSO was used to lyse the cells. The absorbance at $570 \mathrm{~nm}$ was read using a Beckman Coulter ${ }^{\mathrm{TM}}$ model AD 340 reader. The negative control consisted of cells treated with PBS buffer, $\mathrm{pH}$ 7.4. The percentage of cell proliferation was calculated relative to the negative control, which was defined as $100 \%$. Experiments were performed in triplicate.

\section{Results}

\subsection{Protein purification and identification}

Eighteen fractions from A. c. pictigaster crude venom were obtained by cation exchange chromatography (Fig. 1). Fractions 1, 2, 4, 5 and 12-17 showed fibrinolytic activity. Fractions 1, 2, 5 and 12-14 contained hemorrhagic activity. Fractions 1, 2, 12-13 and 17 contained gelatinase activity (Table 1). Then, trans-pecos copperhead crude venom was fractionated using a reverse phase C-18 chromatographic column and two fractions with disintegrin activity were collected at 33\% acetonitrile (Figure 2). The fractions obtained from the trans-pecos copperhead purification were designated as pictistatin 1 and 2.

\subsection{SDS-PAGE}

The fractions isolated from $\mathrm{C} 18$ reverse phase chromatography were compared on a 10-20\% Tricine SDS-PAGE gel. The fractions obtained from the purification showed that pictistatin 1 contained $\mathrm{a} \sim 16.7 \mathrm{kDa}$ single band, under non-reducing conditions, while under reducing conditions, a mass of approximately $7.8 \mathrm{kDa}$ was observed. The fractions obtained from the purification showed that pictistatin 2 contained a $\sim 15.6 \mathrm{kDa}$ single band, under non-reducing conditions, and a $\sim 7.4 \mathrm{kDa}$ single band, under reducing conditions (Figure 3). The non-reduced and reduced results for both fractions suggested dimeric disintegrins.

\subsection{N-terminal sequencing}

The N-terminal amino acid sequencing showed that pictistatin 2 is a heterodimeric disintegrin. On the other hand, pictistatin 1 showed identical amino acid sequence for the first 12 amino acids. Because only the $\mathrm{N}$-terminal amino acid sequence was determined, pictistatin 1 has not been identified as either a homo or heterodimeric 
(Table 2).

\subsection{Inhibition of platelet aggregation}

Pictistatin 1 moderately inhibited ADP-, collagen-, ristocetin-, epinephrine-, and arachidonic acid-induced platelet aggregation in a dose-dependent manner, with an $\mathrm{IC}_{50}$ of $0.98,1.56,0.33,0.62$, and $3.1 \mu \mathrm{M}$, respectively. Pictistatin 2 inhibited ristocetin-, epinephrine-, and arachidonic acid-induced platelet aggregation in a dose-dependent manner with an $\mathrm{IC}_{50}$ of $0.72,0.68$, and $1.42 \mu \mathrm{M}$, respectively. Pictistatin 2 did not inhibit ADP- and collagen-induced aggregation even at very high doses. The strongest inhibition was observed with pictistatin 1 in the presence of ristocetin (Table 3).

\subsection{Proliferation inhibition studies}

None of the isolated disintegrins inhibited the proliferation of BXPC-3, SK-MEL28, T24 or K-562 cells, even at high doses (data not shown).

\section{Discussion}

Agkistrodon contortrix pictigaster crude venom showed different fractions with fibrinolytic, hemorrhagic, and gelatinase activities. This venom is highly proteolytic, and its hemorrhagic activity lies in the action of some metalloproteinase components acting on the extracellular matrix proteins and cell membranes in general. Gelatinase activity, accompanied by the action of hyaluronidase (not tested in this study) allows components of the venom to spread through the tissues to exert its enzymatic action on its predefined targets. At least 10 of the 18 fractions obtained by cation-exchange chromatography were fibrinolytic, showing that this venom has a high activity on fibrin.

However, the primary aim of this project focuses on non-enzymatic venom proteins, the so-called disintegrins. Isolation of disintegrins was accomplished from the venom of species of $A$. controtrix, the trans-pecos copperheads. The disintegrin domain of ADAMs (a disintegrin and metalloproteinase) is unique among adhesion molecules of cell surface [21, 22] and is structurally related to snake venom metalloproteinases (SVMPs), which are the primary factors responsible for hemorrhage and may affect the hemostatic system, thus aiding loss of blood from the victim's vasculature. This lineage of peptides, obtained from snake venoms, have been titled as disintegrins, since they antagonize the activity of membrane proteins called integrins [22], attaching to the 
glycoprotein Ilb-Illa on platelet cells and preventing them to interact with its natural ligands, such as fibrinogen, i.e. inhibiting platelet aggregation at the site of injury and contributing to the bite effect of the hemorrhagic snakes [23, 24]. The ADAM disintegrin domain consists of approximately 90 amino acids [24].

Platelets participate not only in primary hemostasis but also in secondary hemostasis. The process can involve different stages, such as platelet adhesion, platelet aggregation, and procoagulant activity [25]. Platelet aggregation is a crucial step in normal hemostasis. Injury of endothelial cells causes rapid adhesion of platelets, degranulation followed by further activation of platelets. Platelets receptors play a fundamental role in the regulation of platelet aggregation [26]. However, abnormal platelet function is implicated in the pathogenesis of many morbid conditions, such as inflammation, atherosclerosis, and sepsis [25]. On the other hand, disintegrins are among the most potent known natural inhibitors of integrin function. These small peptides have been found to inhibit platelet aggregation, angiogenesis, metastasis, and tumor growth [27]. For this reason, disintegrins could be investigated as therapeutic agents for many pathologies such as inflammation, autoimmune diseases, asthma, osteoporosis, thrombosis and cancer [10].

Two disintegrins (contortrostatin and acostatin) have been isolated from $A$. contortrix [28, 29, 30]. Contortrostin is a homodimer disintegrin whereas acostatin is a heterodimer disintegrin; both containing a RGD motif in each chain $[29,30]$. The first dimeric disintegrin described was contortrostatin, which remains the only disintegrin having two RGD sequences [29]; this homodimer is related to integrins $\alpha \mathrm{II}_{b} \beta_{3}, \alpha_{5} \beta_{1}$, $\alpha_{v} \beta_{3}$, and $\alpha_{v} \beta_{5}$ inhibiting platelet aggregation and cell adhesion to extracellular matrix proteins [29]. Acostatin consisting of 63 and 64 amino acid residues in the alpha and beta chains demonstrated to have the RGD sequence for binding $\alpha \mathrm{I}_{b} \beta_{3}$ [30]. In the present study, we are describing the first isolation and partial characterization of two dimeric disintegrins isolated from A. c. pictigaster.

The N-terminal sequencing information for the two disintegrins isolated in this study revealed one definite heterodimeric disintegrin. One of the disintegrins, pictistatin 1, had identical N-terminal amino acids (Table 1), but does not indicate a homodimeric disintegrin. Pictistatin 1 is a dimeric disintegrin as shown by SDS-PAGE (Fig. 3). The 
non-reduced sample has a molecular weight at about $16 \mathrm{kDa}$, whereas, the reduced sample lies at $\sim 8 \mathrm{kDa}$. Complete amino acid sequencing is necessary to elucidate if it is a homodimer or heterodimer. Both disintegrins in this study were distinct from the previously reported dimeric disintegrins (Table 4; Figure 4). In the venom of $A$. piscivorus piscivorus a disintegrin called applaggin has been isolated, which was a dimeric disintegrin with a perceptible molecular mass of $16 \mathrm{kDa}$ under nonreducing conditions and $8 \mathrm{kDa}$ under reducing conditions as described by SDS-PAGE [31]. In spite of this, Wencel-Drake et al. (1993) [31] proposed that applaggin did not have a dimeric structure supported by mass spectroscopy results.

The acostastin inhibited ADP-induced platelet aggregation in human PRP in a dose-dependent manner. The $\mathrm{IC}_{50}$ value for this disintegrin was $72 \pm 30 \mathrm{nM}$. Subunits of other dimeric disintegrins such as lebein and acostatin [32], EC3 [33], and EMF10 [34] have a high degree of similarity. The chain of acostatin is completely identical to the deduced amino acid sequence of contortrostatin, which is described as homodimeric disintegrin from the same genus snake. However, the same authors that isolated acostatin from A. c. contortrix venom could not isolate homodimeric disintegrins from the $A . p$. piscivorus venom.

Acostatin subunits have identical complete alignment of cysteine residues to EMF10, suggesting that acostatin has the same patterns as the disulfide bridges of EMF10 [35]. Since the alignments of all cysteine residues of acostatin and piscivostatin are identical to those of EMF10, it is considered that the isolated pictistatins from $A$. $c$. pictigaster have the same location of the two intrachain disulfide bridges of EMF10. It is hypothesized that the dimeric disintegrins subunits are encrypted on independent mRNAs.

Our results points to that dimeric disintegrins are extensively extended in Agkistrodon and Vipera venoms, and possibly in addition in the venoms of Viperidae that are copious fonts of monomeric disintegrins. As Calvete (2013) [10] proposed, these large sequence and structural multiplicity, displayed by the diverse subfamilies of disintegrins (Fig. 4) well advise that disintegrins, like toxins from other described venoms [36], have evolved promptly by a mechanism of capacity for adaptation in the evolution determined by positive Darwinian selection. 
Platelets were the first cells investigated in the context of snake venom disintegrins [21]. The majority of discovered snake venom disintegrins contain an RGD or related motif in the active site, and they potently inhibit platelet function. The potency of disintegrins to inhibit platelet aggregation depends on their ability to bind $\alpha \mathrm{II}_{b} \beta_{3}$ integrins. However, the majority of RGD-heterodimeric disintegrins revealed a low affinity to bind $\alpha \mathrm{II}_{b} \beta_{3}$ integrins [37]. The RGD family of disintegrins, which bind and inhibit the physiological functions of RGD-dependent integrins, constitute the largest and most investigated family of snake venom disintegrins [27]. The majority of identified RGD-disintegrins belong to monomeric proteins, although the RGD sequence is also present in certain dimeric disintegrins [27]. All homodimeric disintegrins express an active site RGD motif [27]. However, in the case of the heterodimeric disintegrins, the second subunit usually displays another motif, which participates in the inhibition of other integrins [10, 37].

The platelet aggregation inhibiting activity of the dimeric disintegrins obtained from the purification of trans-pecos copperhead crude venom was tested in this study. Pictistatin 1 moderately inhibited ADP- and collagen-induced platelet aggregation in a dose-dependent manner. In addition, pictistatin 1 and pictistatin 2 subtly inhibited epinephrine- and arachidonic acid-induced platelet aggregation in a dose-dependent manner. On the other hand, Pictistatin 1 and pictistatin 2 inhibited ristocetin-induced platelet aggregation in a dose-dependent manner with much higher activity. The strongest inhibition was observed with pictistatin 1 in presence of ristocetin. The inhibition of platelet aggregation in the presence of collagen and ristocetin may suggest that these proteins might act on $\alpha_{2} \beta_{1}$, GPVI and/or GPIb receptors besides $\alpha \mathrm{II}_{b} \beta_{3}$ integrins [26, 38].

The majority of the monomeric disintegrins are active at nanomolar concentrations [30]. In contrast, similar to that reported by other authors (Table 4), with few exceptions, such as $\mathrm{CC} 8 \mathrm{~A} / \mathrm{CC} 8 \mathrm{~B}$ and contortrostatin, our disintegrins showed activity at micromolar concentration; however, they were found to have a high specificity for platelets, showing no inhibition activity of proliferation on different human cancer cell lines (- including pancreatic carcinoma (BXPC-3), skin melanoma (SK-MEL-28), urinary bladder carcinoma (T24), and leukemia (K-562) (data not shown). Practically all types of blood cells, as well as endothelial cells and cancer cells have receptors for 
disintegrins proteins [37], which can jeopardize one of the most important characteristics of any components with pharmaceutical potential, which specificity. Because of their specificity to platelets, these dimeric disintegrins can be considered an improvement to the current antithrombic therapeutics currently derived from snake venoms (e.g. integrillin and aggrastat). Pictistatin 1 and 2, as integrin platelet inhibitors, could be exploited as antiplatelet agents, and/or have a potential use as prototype for the design and synthesis of radiolabeled peptides ligands in molecular imaging of thromboembolic diseases since, in general, the effectiveness of many drugs is limited by their toxicity to normal cells or by their lack of specificity, which leads to the many common side effects associated with some treatments, such as chemotherapy drugs.

\section{Acknowledgments}

Funding for the project was provided by the NIH/Biological Materials Resource Grant, Viper Resource Grant \# 3P40OD010960-10S1 and 2P40OD010960-11A1 (NNTRC, Texas A\&M University-Kingsville, Dr. E.E. Sanchez). Additional support was provided by the Robert A. Welch Foundation Department Grant, Grant number AC-0006 (TAMUK-Department of Chemistry), the United States Department of Agriculture STEP-UP Grant \#2011-38422-30826 (Dr. Shad Nelson (TAMUK) and Dr. Jonda Halcomb (Del Mar College) and the National Science Foundation, ATE Grant REVISION,DUE 1205059 (Dr. John Hatherill and Dr. Daisy Zhang), Department of Education Title V grant DUE P031C110077. FONACIT (Venezuela) Grant: No 2014000490. We would also like to thank Dr. Daisy Zhang (Del Mar College), Nora Diaz De Leon, and Mark Hockmuller (NNTRC serpentarium curator) and all the NNTRC personnel.

Author contributions: Conceived and designed the experiments: EES, SL, ARA. Performed the experiments: EES, SL, EG, AA, AG, IO, RW, MS, NLU, BG. Contributed materials/analysis tools: EES. Wrote the paper: EES, SL, ARA. All authors analyzed the results and approved the final version of the manuscript. 


\section{References}

[1] Wright AH, Wright AA. Handbook of Snakes of the United States and Canada. $2^{\text {nd }}$ ed. New York: Comstock Pub Assoc; 1994.

[2] Campbell JA, Lamar WW. The Venomous Reptiles of the Western Hemisphere. $2^{\text {nd }}$ ed. Cornell University Press, Ithaca, NY; 2004.

[3] Trikha M, Rote WE, Manley PJ, Lucchesi BR, Markland FS. Purification and characterization of platelet aggregation inhibitors from snake venoms. Thromb Res 1994; 73: 39-52.

[4] Stocker K, Fischer H, Meier J, Brogli M, Svendsen L. Protein C activators in snake venoms. Behring Inst Mitt 1986; 79:37-47.

[5] Hatton MW. Studies on the coagulant enzyme from Agkistrodon rhodostoma venom. Isolation and some properties of the enzyme. Biochem J 1973; 131:799-807.

[6] Soto JG, Powell RL, Reyes SR, Wolana L, Swanson LJ, Sanchez EE, Perez JC. Genetic variation of a disintegrin gene found in the American copperhead snake (Agkistrodon contortrix). Gene 2006; 373:1-7.

[7] Tan NH, Ponnudurai G. A comparative study of the biological activities of venoms from snakes of the genus Agkistrodon (moccasins and copperheads). Comp Biochem Physiol B 1990; 95:577-82.

[8] Johnson EK, Ownby CL. Isolation of a hemorrhagic toxin from the venom of Agkistrodon contortrix laticinctus (broad-banded copperhead) and pathogenesis of the hemorrhage induced by the toxin in mice. Int J Biochem 1993; 25:267-78.

[9] Retzios AD, Markland FS Jr. A direct-acting fibrinolytic enzyme from the venom of Agkistrodon contortrix contortrix: effects on various components of the human blood coagulation and fibrinolysis systems. Thromb Res 1988; 52:541-52.

[10] Calvete, JJ. The continuing saga of snake venom disintegrins. Toxicon 2013; 62: 4049.

[11] Keyler DE, Vandevoort JT. Copperhead envenomations: clinical profiles of three different subspecies. Vet Hum Toxicol 1999; 41:149-152.

[12] NIH. Principles of Laboratory Animal Care. National Institute of Health of United States, Maryland. 1985. 
[13] Sánchez EE, Rodríguez-Acosta A, Palomar R, Lucena SE, Bashir S, Soto JG, Pérez JC. Colombistatin: A disintegrin isolated from the venom of the South American snake (Bothrops colombiensis) that effectively inhibits platelet aggregation and SK-MEL-28 cell adhesion. Arch Toxicol 2009; 83: 271-279.

[14] Sánchez EE, Galán JA, Russell WK, Soto JG, Russell DH, Pérez JC. Isolation and characterization of two disintegrins inhibiting ADP-induced human platelet aggregation from the venom of Crotalus scutulatus scutulatus (Mohave rattlesnake). Toxicol Appl Pharmacol 2006; 212: 59-68.

[15] Sánchez EE, Galán JA, Powell RL, Reyes SR, Soto JG, Russell WK, Russell DH, Pérez JC. Disintegrin, hemorrhagic, and proteolytic activities of Mohave rattlesnake, Crotalus scutulatus scutulatus venoms lacking Mohave toxin. Comp Biochem Physiol C 2005; 141: 124-132.

[16] Huang SY, Perez JC. Comparative study on hemorrhagic and proteolytic activities of snake venoms. Toxicon 1980;18:421-426.

[17] Omori-Satoh T, Sadahiro S, Ohsaka A, Murata R. Purification and characterization of an antihemorrhagic factor in the serum of Trimeresurus flavoviridis, a crotalid. Biochim Biophys Acta 1972; 285:414-426.

[18] Bajwa SS, Kirakossian H, Reddy KN, Markland FS.Thrombin-like and fibrinolytic enzymes in the venoms from the Gaboon viper (Bitis gabonica), eastern cottonmouth moccasin (Agkistrodon p. piscivorus) and southern copperhead (Agkistrodon c. contortrix) snakes. Toxicon 1982; 20:427-32.

[19] Sánchez EE, Lucena SE, Reyes S, Soto JG, Cantu E, Lopez-Johnston JC, Guerrero B, Salazar AM, Rodríguez-Acosta A, Galán JA, Tao WA, Pérez JC. Cloning, expression, and hemostatic activities of a disintegrin, r-mojastin 1, from the Mohave rattlesnake (Crotalus scutulatus scutulatus). Thromb Res 2010; 26: 211-219.

[20] Lucena S, Castro R, Lundin C, Hofstetter A, Alaniz A, Suntravat M, Sánchez EE. Inhibition of pancreatic tumoral cells by snake venom disintegrins. Toxicon 2015; 93C: 136-143.

[21] Blobel CP, White JM. Structure, function and evolutionary relationship of proteins containing a disintegrin domain. Curr Opin Cell Biol 1992; 4:760-765.

[22] Gould RJ, Polokoff MA, Friedman PA, Huang TF, Holt JC, Cook JJ, Niewiarowski 
S. Disintegrins: a family of integrin inhibitory proteins from viper venoms. Proc Soc Exp Biol Med 1990; 195:168-171.

[23] Bjarnason JB, Fox JW. Hemorrhagic metalloproteinases from snake venoms. Pharmacol Ther 1994; 62:325-372.

[24] Seals DF, Courtneidge SA. The ADAMs family of metalloproteases: multidomain proteins with multiple functions. Genes Dev 2003; 17:7-30.

[25] Palomo I, Toro C, Alarcón M. The role of platelets in the pathophysiology of atherosclerosis (Review). Mol Med Rep 2008; 1:179-184.

[26] Semple JW, Freedman J. Platelets and innate immunity. Cell Mol Life Sci 2010; 67: 499-511.

[27] Walsh EM, Marcinkiewicz C. Non-RGD-containing snake venom disintegrins, functional and structural relations. Toxicon 2011; 58: 355-362.

[28] Moiseeva N, Swenson S.D, Markland FS Jr, Bau R. Purification, crystallization and preliminary X-ray analysis of the disintegrin contortrostatin from Agkistrodon contortrix snake venom. Acta Crystallogr D Biol Crystallogr 2002; 58:2122-2124.

[29] Zhou Q, Nakada MT, Brooks PC, Swenson SD, Ritter MR, Argounova S, Arnold C, Markland FS Jr. Contortrostatin, a homodimeric disintegrin, binds to integrin $\alpha \mathrm{v} \beta 5$. Biochem Biophys Res Commun 2000; 267: 350-355.

[30] Moiseeva N, Bau R, Swenson SD, Markland FS Jr, Choe JY, Liu ZJ, Allaire M. Structure of acostatin, a dimeric disintegrin from Southern copperhead (Agkistrodon contortrix contortrix), at $1.7 \AA$ A resolution. Acta Crystallogr D Biol Crystallogr 2008; 64: 466-470.

[31] Wencel-Drake JD, Frelinger AL 3rd, Dieter MG, Lam SC. Arg-Gly-Asp-dependent occupancy of GPIIb/IIIa by applaggin: evidence for internalization and cycling of a platelet integrin. Blood 1993; 81: 62-69.

[32] Gasmi A, Srairi N, Guermazi S, Dekhil H, Karoui H, El Ayeb M. Amino acid structure and characterization of a heterodimeric disintegrin from Vipera lebetina venom. Biochim Biophys Acta 2001; 1547:51-56.

[33] Marcinkiewicz C, Calvete JJ, Marcinkiewicz MM, Raida M, Vijay-Kumar S, Huang Z, Lobb RR, Niewiarowski S. EC3, a novel heterodimeric disintegrin form Echis carinatus venom, inhibits alpha4 and alpha5 integrins in an RGD-independent manner. $\mathrm{J}$ 
Biol Chem 199; 274: 12468-12473.

[34] Marcinkiewicz C, Calvete JJ, Vijay-Kumar S, Marcinkiewicz MM, Raida M, Schick P, Lobb RR, Niewiarowski S. Structural and functional characterization of EMF10, a heterodimeric disintegrin from Eristocophis macmahoni venom that selectively inhibitis 51 integrin. Biochemistry 1999; 38: 13302-13309.

[35] Calvete JJ, Jürgens M, Marcinkiewicz C, Romero A, Schrader M, Niewiarowski S. Disulphide-bond pattern and molecular modelling of the dimeric disintegrin EMF-10, a potent and selective integrin alpha5beta1 antagonist from Eristocophis macmahoni venom. Biochem J 2000; 345:573-81.

[36] Kordis D, Krizaj I, Gubensek F. Functional diversification of animal toxins by adaptative evolution. In: Menez A, editor. Perspectives in Molecular Toxinology, New York: John Wiley \& Sons; 2002, p. 401-419.

[37] Marcinkiewicz C. Applications of snake venom components to modulate integrin activities in cell-matrix interactions. Int J Biochem Cell Biol 2013; 45: 1974-1986.

[38] Jurk K, Kehrel BE. Platelets: physiology and biochemistry. Semin Thromb Hemost 2005; 31: 381-392. 
Table 1. Cation-exchange chromatography from $A$. c. pictigaster crude venom

\begin{tabular}{lllllllllllllllllll} 
Fraction & 1 & 2 & 3 & 4 & 5 & 6 & 7 & 8 & 9 & 10 & 11 & 12 & 13 & 14 & 15 & 16 & 17 & 18 \\
\hline
\end{tabular}

\section{Activities}

Hemorrhagic $++\quad-\quad+\quad-\quad-\quad-\quad-\quad+\quad+\quad+\quad-\quad-\quad-$

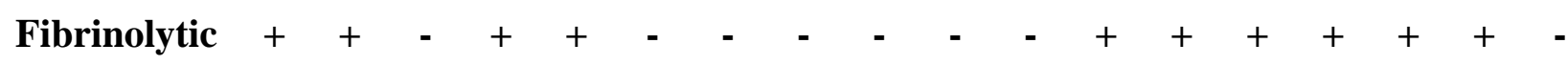

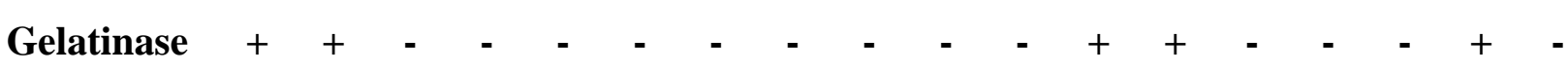

The proteolytic activity was tested (hemorrhagic, fibrinolytic, and gelatinase) for each fraction. The negative signs indicated no activity. 
Table 2. Comparison of $\mathrm{N}$-terminal sequence homology between disintegrins

\begin{tabular}{ccccc}
\hline Peak name & Mass $(\mathrm{kDa})$ & Type of disintegrin & Origin & N-terminal sequence \\
\hline pictistatin 1 & 16.7 & $\mathbb{I}$ & $\begin{array}{l}\text { A.contortrix } \\
\text { pictigaster }\end{array}$ & VQPKNPYCDAAT \\
pictistatin 2 & 15.6 & Heterodimeric & $\begin{array}{l}\text { A.contortrix } \\
\text { pictigaster }\end{array}$ & $\begin{array}{c}\text { VQPANPLCDAAT } \\
\text { DAPANPLCDAA }\end{array}$ \\
& & & T
\end{tabular}

II Dimer disintegrin has not been identified as either a homo or hetero 
Table 3. Platelet aggregation inhibition in presence of pictistatin 1 and pictistatin 2

\begin{tabular}{lcc}
\hline \multicolumn{1}{c}{ Agonist } & Pictistatin $1^{*}$ & Pictistatin 2* \\
\hline ADP & $980 \pm 62 \mathrm{nM}$ & NA \\
Collagen & $1560 \pm 70 \mathrm{nM}$ & NA \\
Ristocetin & $330 \pm 35 \mathrm{nM}$ & $720 \pm 42 \mathrm{nM}$ \\
Epinephrine & $620 \pm 50 \mathrm{nM}$ & $680 \pm 51 \mathrm{nM}$ \\
Arachidonic acid & $3095 \pm 10 \mathrm{nM}$ & $1420 \pm 107 \mathrm{nM}$ \\
\hline
\end{tabular}

*The results are expressed in $\mathrm{IC}_{50}$

NA: No activity 
Table 4. Inhibition of ADP-induced platelet aggregation in presence of dimeric disintegrins

\begin{tabular}{|c|c|c|c|c|}
\hline Disintegrin & Type & Origin & Activity & References \\
\hline CC5 & Homodimer & $\begin{array}{c}\text { North African } \\
\text { Cerastes cerastes }\end{array}$ & $93 \mathrm{nM}^{*}$ & $\begin{array}{l}\text { Calvete et al. } \\
\text { (2002) }\end{array}$ \\
\hline CC8A/CC8B & Heterodimer & $\begin{array}{c}\text { North African } \\
\text { Cerastes cerastes }\end{array}$ & $11 \mathrm{nM}^{*}$ & $\begin{array}{l}\text { Calvete et al. } \\
\text { (2002) }\end{array}$ \\
\hline Contortrostatin & Homodimer & $\begin{array}{l}\text { A. contortrix } \\
\text { contortrix }\end{array}$ & $60 \mathrm{nM}^{*}$ & $\begin{array}{l}\text { Zhou et al. } \\
\text { (2000) }\end{array}$ \\
\hline Bilitoxin 1 & Homodimer & $\begin{array}{c}\text { Agkistrodon } \\
\text { billineatus }\end{array}$ & $\mathrm{NA}^{*}$ & $\begin{array}{l}\text { Nikai et al. } \\
\text { (2000) }\end{array}$ \\
\hline Piscivostatin & Heterodimer & $\begin{array}{c}\text { A. piscivorus } \\
\text { piscivorus }\end{array}$ & $103 \mathrm{nM}^{*}$ & $\begin{array}{c}\text { Okuda and } \\
\text { Morita (2001) }\end{array}$ \\
\hline Acostatin & Heterodimer & A. c. contortrix & $103 \mathrm{nM}^{*}$ & $\begin{array}{c}\text { Okuda and } \\
\text { Morita (2001) }\end{array}$ \\
\hline EC3A/EC3B & Heterodimer & Echis carinatus & $1000 \mathrm{nM}^{*}$ & $\begin{array}{c}\text { Marcinkiewicz et } \\
\text { al. (1999a) }\end{array}$ \\
\hline $\begin{array}{c}\text { EMF10A/EMF10 } \\
\text { B }\end{array}$ & Heterodimer & $\begin{array}{c}\text { Eristocophis } \\
\text { macmahoni }\end{array}$ & $1600 \mathrm{nM}^{*}$ & $\begin{array}{c}\text { Marcinkiewicz et } \\
\text { al. (1999b) }\end{array}$ \\
\hline EC6A/EC6B & Heterodimer & Echis carinatus & $>1000 \mathrm{nM}^{*}$ & $\begin{array}{l}\text { Marcinkiewicz et } \\
\text { al. (2000) }\end{array}$ \\
\hline Lebein & Heterodimer & Vipera lebetina & $160 \mathrm{nM}^{*}$ & $\begin{array}{l}\text { Gasmi et al. } \\
\text { (2001) }\end{array}$ \\
\hline Pictistatin1 & dI & A. c. pictigaster & $980 \mathrm{nM}^{*}$ & This study \\
\hline Pictistatin 2 & Heterodimer & A. c. pictigaster & $\mathrm{NA}^{\ddagger}$ & This study \\
\hline
\end{tabular}

*The activity was measured using platelet rich plasma (PRP)

* The activity was measured using whole blood

NA: No activity

II Dimer disintegrin has not been identified as either a homo or hetero 


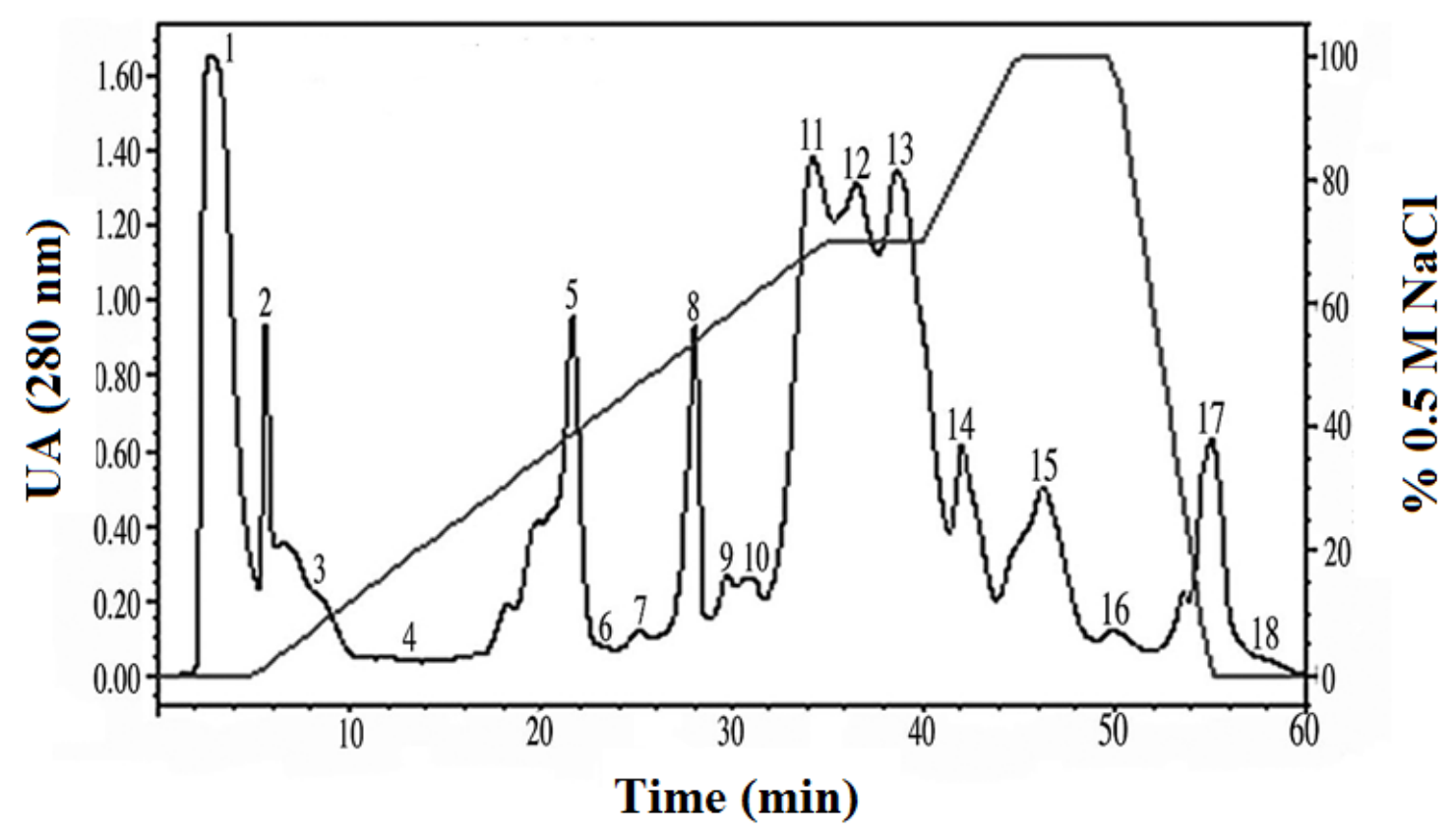

Fig. 1. Cation-exchange chromatography from $A$. $c$. pictigaster venom. Five hundred microliters of $A$. c. pictigaster venom $(60 \mathrm{mg} / \mathrm{mL})$ was injected to a cationic exchange HPLC column Waters ${ }^{\mathrm{TM}}$ SP 5PW $(75 \times 7.5 \mathrm{~mm})$. The fractions were separated with a $0.02 \mathrm{M}$ sodium phosphate buffer, $\mathrm{pH} 6.2$, containing $0.5 \mathrm{M} \mathrm{NaCl}$. The separation required 60 minutes with a flow rate of $1.0 \mathrm{~mL} / \mathrm{min}$. The absorbance was measured at $280 \mathrm{~nm}$ by a Waters ${ }^{\mathrm{TM}} 2487$ Dual absorbance detector. The proteolytic activity was tested (hemorrhagic, fibrinolytic, and gelatinase) for each fraction. 


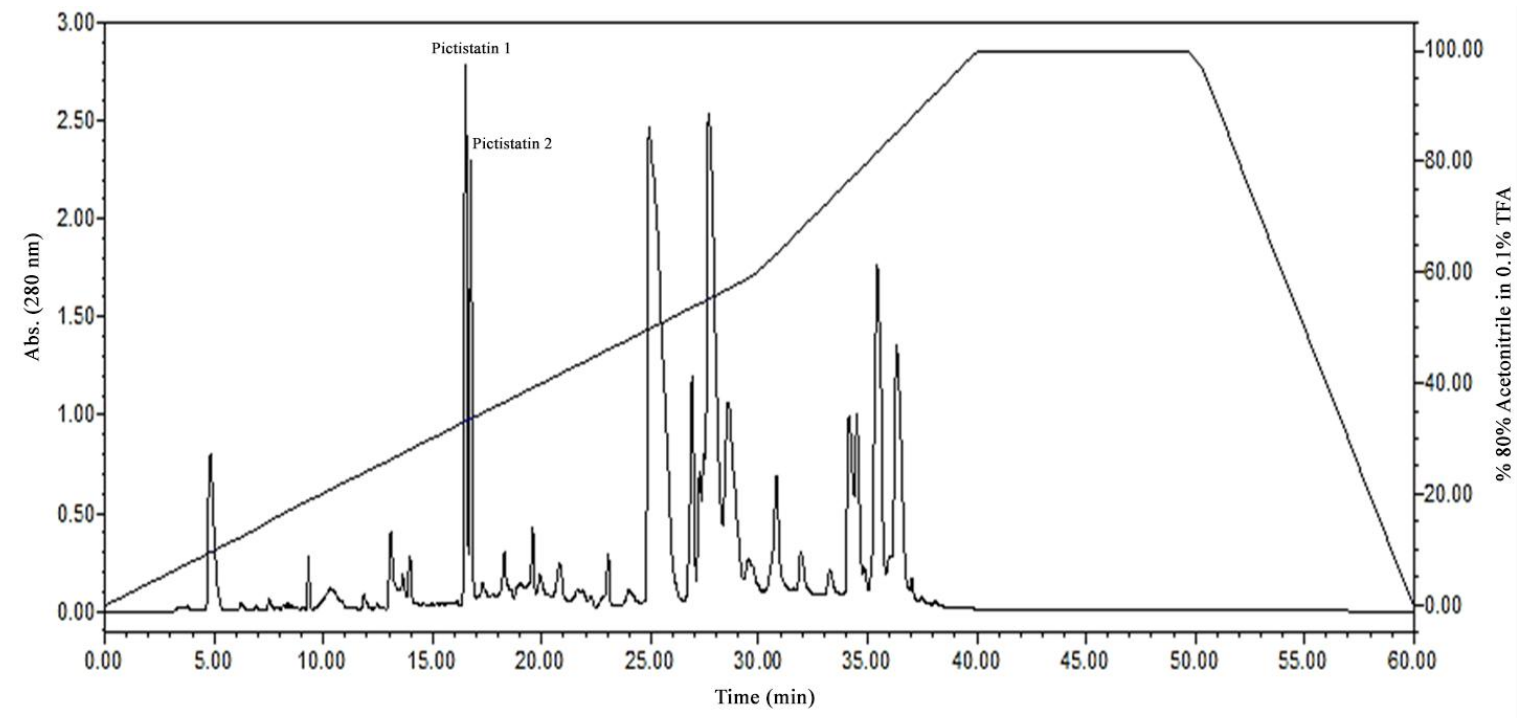

Fig. 2. Reverse phase C18 chromatography of venom from A. c. pictigaster venom. Two hundred microliters $(50 \mathrm{mg} / \mathrm{mL})$ of venom was injected in a Higgins Analytical, Inc. Proto $300 \mathrm{C} 185 \mu \mathrm{m}$ HPLC column $(250 \times 4.6 \mathrm{~mm})$ using Waters ${ }^{\mathrm{TM}} 1525$ binary HPLC pumps. Protein detection was at $280 \mathrm{~nm}$ by a Waters ${ }^{\mathrm{TM}} 2487$ Dual absorbance detector. The fractions were separated with $80 \%$ acetonitrile in $0.1 \%$ triflouroacetic acid (TFA). Data acquisition was accomplished by Waters ${ }^{\mathrm{TM}}$ Breeze software. The fractions designated as pictistatin 1 and 2 obtained with $33 \%$ acetonitrile were tested for inhibition of platelet aggregation. 


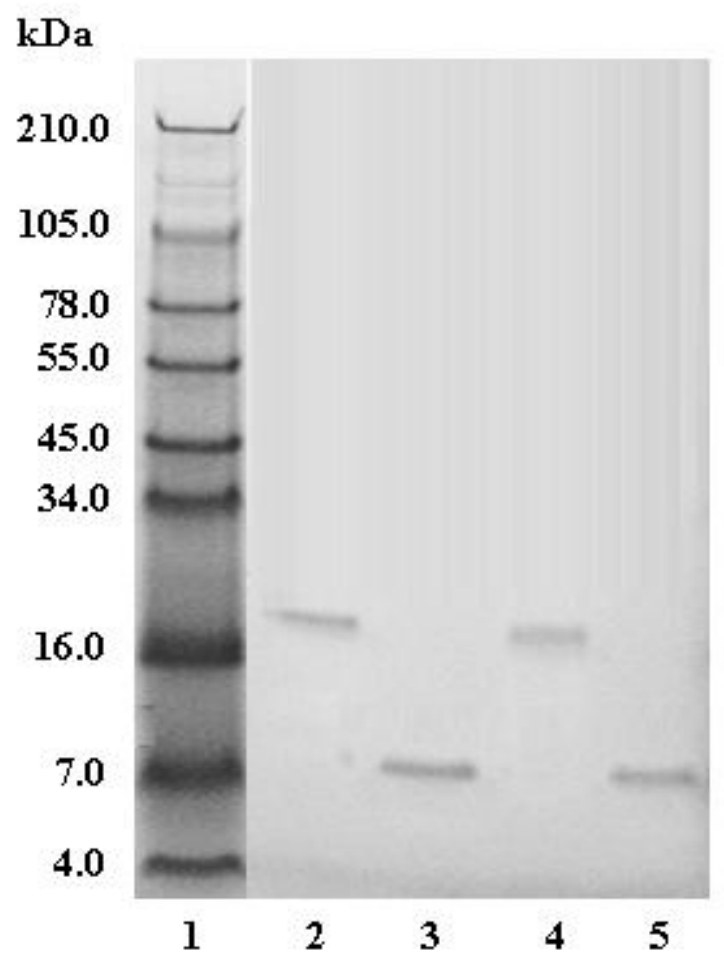

Fig. 3. SDS-PAGE analysis of $A$. c. pictigaster venom fractions from C18 HPLC column. Venom fractions $(20 \mu \mathrm{g})$ were run on 10-20\% Tricine SDS-PAGE under nonreducing and reducing conditions at $125 \mathrm{~V}$ for $90 \mathrm{~min}$. The gel was stained with Simply Blue Safe Stain for $1 \mathrm{~h}$ and distained overnight with Milli-Q water. -Lane 1: SeeBlue Plus2 Markers (Invitrogen ${ }^{\mathrm{TM}}$ ); Lane 2: pictistatin 1 (non-reduced); lane 3: pictistatin 1 (reduced); lane 4: pictistatin 2 non-reduced; lane 5: pictistatin 2 reduced. (reduced) 


\begin{tabular}{|c|c|}
\hline \multirow[t]{2}{*}{ Majority } & $----N S A X P C-C D P V T-$ \\
\hline & 10 \\
\hline Pictistatin1. & \\
\hline Pictistatin2a & \\
\hline Pictistatin2b & \\
\hline AcostatinA & \\
\hline AcostatinB & \\
\hline Bilitoxin-1 & --- \\
\hline CC5A & \\
\hline CC5B & \\
\hline CC8A & \\
\hline CC8B & \\
\hline Contortrostati & \\
\hline EC3A & \\
\hline EC3B & \\
\hline $\mathrm{EC6A}$ & -- \\
\hline EC6B & --- \\
\hline EMF10A & -- \\
\hline EMF10B & $-E L$ \\
\hline Gabonin-1\&2B & \\
\hline Gabonin-1A & \\
\hline Gabonin-2A & --- \\
\hline Lebein & --- \\
\hline PVSA & $--G A$ \\
\hline PVSB & ESDFI \\
\hline
\end{tabular}

Fig. 4. Comparison of the first $12 \mathrm{~N}$-terminal amino acids of snake venom dimeric disintegrins. Clustal W method using MegAlign (DNAStar) was used to align sequences. 


\section{Legends}

Fig. 1. Cation-exchange chromatography from $A$. $c$. pictigaster venom. Five hundred microliters of $A$. c. pictigaster venom $(60 \mathrm{mg} / \mathrm{mL})$ was injected to a cationic exchange HPLC column Waters TM SP 5PW $(75 \times 7.5 \mathrm{~mm})$. The fractions were separated with a $0.02 \mathrm{M}$ sodium phosphate buffer, $\mathrm{pH} 6.2$, containing $0.5 \mathrm{M} \mathrm{NaCl}$. The separation required 60 minutes with a flow rate of $1.0 \mathrm{~mL} / \mathrm{min}$. The absorbance was measured at $280 \mathrm{~nm}$. The proteolytic activity was tested (hemorrhagic, fibrinolytic, and gelatinase) for each fraction.

Fig. 2. Reverse phase C18 chromatography of venom from $A$. c. pictigaster venom. Two hundred microliters $(50 \mathrm{mg} / \mathrm{mL})$ of venom was injected in a Higgins Analytical, Inc. Proto $300 \mathrm{C} 185 \mu \mathrm{m}$ HPLC column $(250 \times 4.6 \mathrm{~mm})$ using Waters ${ }^{\mathrm{TM}} 1525$ binary HPLC pumps. Protein detection was at $280 \mathrm{~nm}$ by a Waters ${ }^{\mathrm{TM}} 2487$ Dual absorbance detector. The fractions were separated with $80 \%$ acetonitrile in $0.1 \%$ triflouroacetic acid (TFA). Data acquisition was accomplished by Waters ${ }^{\mathrm{TM}}$ Breeze software. The fractions designated as pictistatin 1 and 2 obtained with $33 \%$ acetonitrile were tested for inhibition of platelet aggregation.

Fig. 3. SDS-PAGE analysis of A.c. pictigaster venom fractions from C18 HPLC column. Venom fractions $(20 \mu \mathrm{g})$ were run on 10-20\% Tricine SDS-PAGE under nonreducing and reducing conditions at $125 \mathrm{~V}$ for $90 \mathrm{~min}$. The gel was stained with Simply Blue Safe Stain for $1 \mathrm{~h}$ and distained overnight with Milli-Q water. -Lane 1: SeeBlue Plus2 Markers (Invitrogen ${ }^{\mathrm{TM}}$ ); Lane 2: pictistatin 1 (non-reduced); lane 3: pictistatin 1 (reduced); lane 4: pictistatin 2 (non-reduced); lane 5: pictistatin 2 (reduced).

Fig. 4. Comparison of the first $12 \mathrm{~N}$-terminal amino acids of snake venom dimeric disintegrins. Clustal W method using MegAlign (DNAStar) was used to align sequences. 